\title{
A construção do direito ao desenvolvimento e sua aplicação mediante as políticas públicas de sustentabilidade
}

Priscila Benelli Walker ${ }^{1}$

\section{Resumo}

O tema do presente artigo é a evolução histórica do direito ao desenvolvimento sob a perspectiva do direito internacional e sua aplicação nas políticas públicas. O objetivo central é analisar o processo histórico de construção do direito ao desenvolvimento, inicialmente relacionado apenas a crescimento econômico e demonstrar nesse processo o seu aperfeiçoamento e sua ampliação para abarcar outros aspectos da vida humana além de permitir a realização plena de outros direitos e liberdades. Através da análise das principais declarações e pactos internacionais, tais como o Pacto Internacional sobre Direitos Econômicos, Sociais e Culturais, a Declaração sobre Direito ao Desenvolvimento e a Declaração sobre Meio Ambiente e Desenvolvimento, procurou-se demonstrar que o princípio jurídico do desenvolvimento sustentável é resultado de um consenso internacional e de um sistema normativo internacional de proteção ambiental. $\mathrm{Na}$ segunda parte do artigo, pretendeu-se examinar brevemente as dimensões jurídicas das políticas públicas na realização dos direitos humanos bem como apresentar os atores que participam de sua formulação, aplicação e avaliação. Por fim, trazendo o princípio jurídico do desenvolvimento sustentável construído no direito internacional à nossa realidade política, econômica e social, o texto avaliou algumas políticas públicas brasileiras de sustentabilidade relacionadas à defesa do meio ambiente e à segurança alimentar. O valor do presente artigo encontra-se justamente na combinação do princípio jurídico do desenvolvimento sustentável construído no direito internacional com a sua aplicação, mediante políticas públicas de sustentabilidade e a demonstração prática dessa combinação mediante avaliação do Plano de Ação para Prevenção e Controle do Desma-

\footnotetext{
1 Mestranda em Direito pela UNESP na área de Mercado e Relações Internacionais. Bacharel em Direito pela USP. LLM em International Business Transactions pela University College London.
} 
tamento da Amazônia Legal e das políticas públicas relacionadas à segurança alimentar no Brasil.

Palavras-chave: Direito ao desenvolvimento. Direitos humanos. Políticas públicas. Desenvolvimento sustentável.

\section{Introdução}

O objetivo do presente trabalho é propor uma reflexão a respeito da construção histórica do direito ao desenvolvimento no âmbito do Direito Internacional e a sua efetivação mediante as políticas públicas de sustentabilidade.

Inicialmente, será analisado o processo histórico de construção do conceito de desenvolvimento, a partir de sua concepção meramente econômica até a sua ampliação como desenvolvimento sustentável.

Em um segundo momento, será exposto como a questão do desenvolvimento tem sido relevante no âmbito do Direito Internacional. Vale dizer, será analisado o direito ao desenvolvimento inicialmente na esfera das relações econômicas entre os países desenvolvidos e os países em desenvolvimento e, posteriormente, a sua passagem para o campo jurídico dos direitos humanos, abarcando aspectos sociais, políticos e culturais da vida humana até a sua evolução com a proteção do meio ambiente, acrescendo-lhe o atributo da sustentabilidade.

Por fim, serão desenvolvidas breves reflexões acerca da importância das políticas públicas e os desafios para se assegurar um desenvolvimento sustentável.

\section{Desenvolvimento}

Quando se questiona a respeito do que seja desenvolvimento, a primeira resposta tende a relacionar desenvolvimento a crescimento econômico. Essa resposta simplista decorre da visão reducionista e míope de que o desenvolvimento 
seria uma consequência natural do crescimento econômico. Essa visão "otimista ingênua" é defendida pelos fundamentalistas do mercado, os quais limitam a ideia de desenvolvimento à sua face econômica e se utilizam de indicadores tradicionais tais como Produto Interno Bruto per capita, índices acerca do desempenho do mercado acionário, cotações de moedas estrangeiras, ratings de agências internacionais de classificação de risco e dados da saúde das contas públicas e externas para medir o que consideram desenvolvimento.

Segundo Ignacy Sachs:

As for the market fundamentalists, they implicitly consider development as a redundant concept. In their view, development will occur as a natural result of economic growth thanks to the trickle down effect. There is no need for development theory. It is enough to apply modern economics, an ahistorical and universally valid discipline. ${ }^{3}$

Em nome do tão aclamado crescimento econômico e das promessas de desenvolvimento trazidas como sua consequência natural, muitos regimes autoritários foram justificados, assim como foram justificadas reformas para estabilidade monetária, controle de inflação e equilíbrio de contas públicas. E a quantos sacrifícios foram submetidas as classes mais pobres e mobilizados os países periféricos com a promessa de que o crescimento econômico levaria à melhoria da distribuição de renda e às benesses do sistema capitalista das economias centrais.

A concepção de desenvolvimento como crescimento econômico não foi questionada até a década de 60 do século XX, porém, o surgimento de evidên-

2 Denominação utilizada por José Eli da Veiga. In: VEIGA, José Eli da. Desenvolvimento sustentável: o desafio do século XXI. 3. ed. [Rio de Janeiro]: Garamond, 2008.

3 SACHS, Ignacy. Inclusive development strategy in an era of globalization. Working Paper, Geneva, n. 35, p. 9, maio 2004. Disponível em: <http://papers.ssrn.com/sol3/papers. cfm?abstract_id=980233 >. Acesso em:03 dez.2010. "Para os fundamentalistas do mercado, eles implicitamente consideram desenvolvimento como um conceito redundante. $\mathrm{Na}$ sua visão, desenvolvimento ocorrerá como resultado natural do crescimento econômico graças ao efeito em cascata. Não há necessidade de uma teoria sobre desenvolvimento. Já é suficiente a aplicação da disciplina economia moderna, a histórica e universalmente válida" (tradução nossa). 
cias $^{4}$ de que o intenso crescimento econômico não se traduziu necessariamente em maior acesso de população pobres a bens materiais e culturais fez com que essa concepção fosse reavaliada.

Em oposição direta à concepção de desenvolvimento como crescimento econômico, autores como Giovanni Arrighi procuraram desconstruir a ideia de desenvolvimento, demonstrando que as economias periféricas nunca seriam desenvolvidas no sentido de similares às economias centrais do sistema capitalista. Segundo José Eli da Veiga, ${ }^{5}$ os esforços de desconstrução da ideia de desenvolvimento nunca chegaram a apontar para uma verdadeira alternativa ao desejo coletivo de evolução e de progresso que lhes é intrínseco.

Tendo em vista o rol de problemas herdados do século XX, as drásticas mudanças políticas e o acirramento do capitalismo individualista, a desregulamentação crescente dos mercados, as políticas econômicas do Consenso de Washington e os efeitos deletérios do neoliberalismo, levando à concentração de renda, ao aumento da miséria e ao acirramento das tensões sociais, tudo isso acrescido pela desmesurada degradação ambiental, fez-se necessária a busca por uma nova proposta de desenvolvimento. Uma proposta que não se limite às questões técnicas e economicistas dos otimistas ingênuos, nem deixe de oferecer sugestões como o posicionamento dos pessimistas estéreis.

4 Para uma visão ampla e interessante sobre a superação da análise puramente econômica do desenvolvimento. BORGES, Daniel Damásio. Ética e economia: fundamentos para uma reaproximação. In: AMARAL JUNIOR, A. (Org.). Direito internacional e desenvolvimento. Barueri: Manole, 2005. p. 1-51.

5 José Eli da Veiga utiliza o termo "pessimista estéril” para esse posicionamento acerca do desenvolvimento. Essa visão vê o desenvolvimento como uma ilusão, uma crença, um mito ou mecanismo de manipulação ideológica para perpetuar as assimétricas relações entre as minorias dominantes e as maiorias dominadas, nos países e entre países, e não oferece sugestões sobre o que deveria ser feito nas próximas décadas para superar os dois principais problemas herdados do século $\mathrm{XX}$, apesar dos seus progressos científicos e técnicos sem precedentes: desemprego em massa e desigualdades crescentes. VEIGA, José Eli da. Desenvolvimento sustentável: o desafio do século xxi. 3. ed. [Rio de Janeiro]: Garamond, 2008. p. $79-80$. 
A nova concepção do que venha a ser desenvolvimento visa promover a inclusão social, o bem estar econômico e a preservação dos recursos naturais, mediante uma reaproximação da ética (como eixo central) e da economia. Essa proposta pode ser denominada "Desenvolvimento Sustentável" e possui cinco dimensões: política, social, ambiental, econômica e territorial.

Alguns dos defensores do conceito "Desenvolvimento Sustentável” são: o economista Ignacy Sachs, o ganhador do prêmio Nobel de Economia, Amartya Sen, isso sem deixar de prestar homenagem ao economista brasileiro Celso Furtado que, na década de 70, prenunciou o tema da sustentabilidade no livro "O mito do desenvolvimento econômico".

O economista Ignacy Sachs defende na problemática do Desenvolvimento Sustentável o enfoque nas questões do trabalho, da inclusão social, das políticas públicas, da distribuição de renda, a fim de que o desenvolvimento possa permitir que cada indivíduo revele suas capacidades, seus talentos e sua imaginação na busca da autorrealização, mediante esforços coletivos e individuais, combinação de trabalho autônomo e heterônomo e de tempo gasto em atividades não econômicas. Nessa linha, aspectos qualitativos são essenciais, tais como prestação adequada de serviços públicos, padrões dignos de moradia e maneiras viáveis de produzir meios de vida que não dependam de esforços excessivos e extenuantes por parte de seus produtores e de empregos mal remunerados.

Nessa mesma linha de compreensão do processo de desenvolvimento, o indiano Amartya Sen, ganhador do prêmio Nobel de Economia de 1998, rejeita a visão "sangue, suor e lágrimas" "6 do desenvolvimento, em favor de uma concepção voltada para expansão das liberdades humanas e suas capacidades. O desenvolvimento requer que sejam removidas as principais fontes de privação de liberdade:

${ }^{6}$ No artigo, SEN, Amartya. Development thinking at the beginning of the $21^{\text {st }}$ Century. Paper presented at a conference on 'Development Thinking Practice', of the InterAmerican Bank, Washington, Sept. 1996. Disponível em: <http://papers.ssrn.com/sol3/ papers.cfm?abstract_id=1126934>. Acesso em: 03 dez. 2010. Amartya Sen faz uma breve análise da mudança de compreensão do processo de desenvolvimento nos últimos anos e apresenta uma série de políticas públicas e reformas relacionadas à educação, à previdência social, ao sistema de saúde e reforma agrária, como mecanismos para o desenvolvimento. 
pobreza e tirania, carência de oportunidades econômicas e destituição social sistemática, negligência dos serviços públicos e intolerância ou interferência de Estados repressivos.

Em seu livro "Desenvolvimento como Liberdade", Amartya Sen analisa que a privação de liberdade vincula-se estreitamente à carência de serviços públicos e de assistência social - ausência de programas epidemiológicos, sistema planejado de assistência médica e educação ou de instituições eficazes para a manutenção da paz e da ordem locais. Já a violação de liberdade resulta diretamente de uma negação das liberdades políticas e civis por regimes autoritários e de restrições impostas à liberdade de participar da vida social, política e econômica da comunidade.

Além disso, Amartya Sen analisa os mecanismos existentes para financiar a melhoria da qualidade de vida, a despeito dos baixos níveis de renda da população. Segundo Sen, não há necessidade de se esperar pelo longo período de crescimento econômico que levará um Estado a ser muito rico antes de lançar-se na rápida expansão da educação básica e dos serviços de saúde, o financiamento pode se dar mediante um programa adequado de serviços sociais conduzido pelo custeio público.

Por fim, pretende-se concluir que a proposta de desenvolvimento vai desde a proteção dos direitos humanos até o aprofundamento da democracia, buscando assim a reaproximação entre ética, política e economia. Os mecanismos disponíveis para auferir o desenvolvimento aliam aspectos políticos, econômicos e sociais da vida humana. ${ }^{7}$

\footnotetext{
7 Exemplos demecanismos para mediro desenvolvimento são: (i) Índice de Desenvolvimento Humano (IDH) do Programa das Nações Unidas para o Desenvolvimento (PNDU) - o qual não se resume à renda per capita ou à renda por trabalhador; (ii) Índice Paulista de Responsabilidade Social (IPRS) - não há média final e classificação municipal em grupos distintos; e (iii) DNA-Brasil do NEPP da Unicamp - composto por 24 indicadores em sete dimensões: bem-estar econômico; competitividade econômica; condições socioambientais; educação; saúde; proteção social básica; e coesão social. Para uma visão mais detalhada, ver José Eli da Veiga, capítulo II Como pode ser medido o desenvolvimento. In: VEIGA, José Eli da. Desenvolvimento sustentável: o desafio do século XXI. 3. ed. [Rio de Janeiro]: Garamond, 2008.
} 


\section{Questão do desenvolvimento como tema do direito internacional}

O presente tópico tem por objetivo demonstrar a importância que o desenvolvimento adquiriu nos últimos anos no âmbito internacional, deixando de estar limitado às questões internas dos Estados e integrando também a esfera do sistema econômico internacional. Adicionalmente, pretende-se apontar as origens do princípio jurídico do desenvolvimento sustentável resultado de um consenso internacional e de um sistema normativo internacional de proteção ambiental.

O direito ao desenvolvimento na esfera internacional surge como uma reivindicação dos países em desenvolvimento. ${ }^{8}$ Num primeiro momento, como pleito dos territórios recém-descolonizados após a Segunda Guerra Mundial, vários chefes de Estado da África e Ásia, representando esse novo grupo, reuniram-se na Conferência de Bandung (realizada em abril de 1955) para preservar a soberania das nações recém-formadas, a livre determinação dos povos e a criação de medidas de cooperação mútua.

Posteriormente, com o Movimento dos Não-Alinhados, as ideias de solidariedade entre os países em desenvolvimento e de ação coletiva foram revigoradas, podendo-se dizer que, após a Conferência de Alger (1973), os Estados que integraram esse movimento tornaram-se um importante grupo de pressão para a reorganização do sistema econômico internacional. Porém, foi na primeira Conferência da Organização das Nações Unidas sobre Comércio e Desenvolvimento -

8 Para Fernando Antonio Amaral Cardia "a década de 60 viu nascer o Direito do Desenvolvimento como um programa normativo de cooperação em diversas áreas das relações econômicas, com vistas a superar as profundas diferenças de desenvolvimento existentes entre os povos do mundo [...] e três são os eventos mais importantes de solidariedade entre os Estados do Terceiro Mundo: a Conferência de Bandoeng, o Movimento dos Não Alinhados e a constituição do Grupo dos 77” CARDIA, Fernando Antonio Amaral. Uma breve introdução à questão do desenvolvimento como tema de direito internacional. In: AMARAL JUNIOR, A.(Org.). Direito internacional e desenvolvimento. Barueri: Manole, 2005. p. 62. 
CNUCED, 9 em 1964, que os países em desenvolvimento da África, Ásia e América, naquele momento, organizados em bloco - o Grupo dos 77 - institucionalizaram a nova divisão do mundo econômico e passaram a buscar a coordenação em suas políticas econômicas, almejando criar condições para alcançar desenvolvimento econômico ${ }^{10} \mathrm{e}$ instaurar uma nova ordem econômica internacional em contraposição ao sistema inaugurado em Bretton Woods. ${ }^{11}$

A Nova Ordem Econômica Internacional pretendida pelos países em desenvolvimento deveria ser formada por relações mais justas entre os países desenvolvidos e em desenvolvimento e "fundada na equidade, na igualdade soberana, na interdependência, no interesse comum e na cooperação entre todos os Estados". ${ }^{12}$

Além da CNUCED, os países em desenvolvimento lograram em 1965 aprovar a criação de um Programa das Nações Unidas para o Desenvolvimento (PNUD), cujo objetivo principal "tem sido o de promover o desenvolvimento

9 A UNCTAD (CNUCED) é um órgão permanente da Assembléia Geral da ONU criado pelos Estados menos desenvolvidos com o objetivo de modificar a própria condição econômica desses Estados, visando o desenvolvimento, crescimento econômico e o comércio internacional justo. A UNCTAD oferece cursos de capacitação aos países em desenvolvimento, produz relatórios e princípios sobre comércio internacional e desenvolvimento e batalha para superação das desigualdades econômicas entre os Estados. Entretanto, a partir da criação da Organização Mundial do Comércio (OMC), sofreu certo esvaziamento e perda de sua força política, isso também em decorrência da mudança do cenário político internacional.

${ }^{10} \mathrm{O}$ cenário político internacional (período da Guerra Fria e das polaridades definidas) permitiu a mobilidade ("gravitação") e a obtenção por parte dos países em desenvolvimento de uma série de conquistas junto às duas principais potências mundiais - EUA e URSS.

${ }^{11}$ A ordem econômica internacional decorrente do pós Segunda Guerra Mundial tem como principais pilares as instituições concebidas na Conferência Monetária e Financeira de Bretton Woods (1944): o Fundo Monetário Internacional e o Banco Internacional para a Reconstrução e o Desenvolvimento. O terceiro pilar de sustentação, a Organização Internacional do Comércio,acabou por não ser estabelecida naquele momento, porém, o Acordo Geral de Tarifas e Comércio (doravante denominado GATT), inicialmente provisório, funcionou também como um órgão internacional e foro de negociações multilaterais. A Organização Mundial do Comércio (OMC), constituída quase 50 anos depois da conferência, completa o terceiro pilar da ordem internacional construída em Bretton Woods.

${ }^{12}$ Resolução 3.201 - S-VI da Organização das Nações Unidas. 
social e a eliminação da pobreza, desenvolvimento da administração da coisa pública, energia sustentável e meio ambiente, ciência e tecnologia." ${ }^{13}$

Após a década de $80^{14}$ do século XX, a relação entre os países desenvolvidos e em desenvolvimento tomou um novo rumo. Os países em desenvolvimento, em decorrência da crise econômica mundial de 1982, tiveram um aumento significativo das suas dívidas externas e sofreram com altos índices inflacionários, e as negociações internacionais entre os Estados passaram a refletir soluções pontuais e, diferentemente das negociações em bloco, muitos países em desenvolvimento e desenvolvidos celebraram acordos bilaterais de cooperação.

Na década de 90, o receituário proposto pelo Consenso de Washington tinha como características centrais a liberalização comercial e de capitais, a privatização e a desregulamentação da atividade econômica, ${ }^{15}$ acentuando as características do liberalismo sob nova cunhagem - neoliberalismo. ${ }^{16}$

Acrescente-se nesse cenário o papel cada vez mais significativo das empresas multinacionais, as quais enfraqueceram a soberania dos Estados e passaram a participar de forma significativa tanto na esfera econômica quanto na esfera política das relações internacionais e locais.

O enfraquecimento dos países em desenvolvimento no cenário econômico e político internacional após a década de 80 , as consequências da globaliza-

${ }^{13}$ MAGALHÃES, José Carlos de. Direito econômico internacional. Curitiba: Juruá, 2009. p.85.

${ }^{14}$ Importante ressaltar as particularidades econômicas e políticas do cenário internacional que se iniciaram na década de 80: O cenário político e econômico internacional são marcados pelo fim da Guerra Fria e pela derrocada do bloco comunista, bem como pela crise econômica mundial de 1982 e pela política econômica neoliberal de Margaret Thatcher (Inglaterra) e Ronald Reagan (EUA).

${ }^{15}$ FARIA José Eduardo (Org.). Direito e globalização econômica: implicações e perspectivas. Itaim Bibi, SP: Malheiros, 1996.

${ }^{16} \mathrm{O}$ neoliberalismo levou no campo político à hipertrofia do Poder Executivo e pela atrofia dos demais poderes, pelo Estado mínimo e uma pretensa defesa do sufrágio universal e da democracia; no campo econômico - pelas privatizações e desregulamentação da economia e do setor produtivo, pela propriedade privada como valor único e maior, e, no campo social - pela forte exclusão das classes populares. 
ção econômica, o fortalecimento das empresas multinacionais e a acentuação das desigualdades geradas pelo capitalismo especulativo são exemplos de fatores que levaram ao enfraquecimento do princípio do desenvolvimento e de organismos internacionais que buscavam uma nova ordem econômica internacional.

Paralelamente, ocorreu uma mudança de tratamento do direito ao desenvolvimento. Antes, o direito ao desenvolvimento estava restrito às relações econômicas internacionais entre Estados e, mediante declarações e acordos internacionais, o direito ao desenvolvimento passa a ter relevância no campo jurídico dos direitos humanos. Em decorrência dessa estruturação jurídica do direito ao desenvolvimento, o princípio passa então a abarcar todos os aspectos da vida humana (social, cultural, político) e não só o econômico. ${ }^{17}$

A consagração da temática do desenvolvimento na ordem internacional é resultado de lutas sociais, de movimentos encabeçados por organizações não-governamentais, pela sociedade civil e por alguns grupos constituídos por países em desenvolvimento. ${ }^{18}$ Esses atores questionam a não-distribuição das melhorias prometidas pela ordem econômica internacional, a distribuição desigual e injusta dos ganhos decorrentes do livre-comércio e a ilusão do progresso material prometido, que trouxe o aumento da desigualdade e concentração de renda que gerou o aumento da pobreza e miséria urbana, exportadas dos campos para as cidades.

\footnotetext{
${ }^{17}$ Conforme analisado por Fernando Antonio Amaral Cardia: "Paralelamente a essa mudança nas características do direito do desenvolvimento, ocorre outro fenômeno importantíssimo para a consagração da temática do desenvolvimento na ordem internacional: a inclusão do desenvolvimento no discurso dos direitos humanos, com a estruturação jurídico normativa de um direito ao desenvolvimento". CARDIA, Fernando Antonio Amaral. Uma breve introdução à questão do desenvolvimento como tema de direito internacional. In: AMARAL JUNIOR, A.(Org.). Direito internacional e desenvolvimento. Barueri: Manole, 2005. p. 62.

${ }^{18}$ Exemplo de grupos formados por países em desenvolvimento que tiveram papel importante nas negociações internacionais da OMC são: Grupo dos 20 (sendo os principais países: Brasil, Índia) e Grupo de CAIRNS (Brasil, Austrália, Canadá, Argentina e Uruguai).
} 
A fim de demonstrar o processo de construção dos direitos humanos ${ }^{19} \mathrm{e}$ a consolidação jurídica do direito ao desenvolvimento como um direito fundamental, passa-se a analisar o Pacto Internacional sobre Direitos Econômicos, Sociais e Culturais (1966) que detalhou e "juridicizou"20 o conteúdo da Declaração Universal de 1948, no que tange a tais direitos e pode ser considerado um marco na construção ampliada do direito ao desenvolvimento. Serão analisadas ainda a Declaração sobre Direito ao Desenvolvimento (1986), a Declaração de Viena (1993) e, por fim, a Declaração sobre Meio Ambiente e Desenvolvimento (1992).

\section{Conforme nos ensina o Prof. Fábio Konder Comparato:}

A elaboração de dois tratados [Pacto Internacional sobre Direitos Econômicos, Sociais e Culturais e Pacto Internacional sobre Direitos Civis e Políticos] e não de um só, compreendendo o conjunto dos direitos humanos segundo o modelo da Declaração Universal de 1948, foi o resultado de um compromisso diplomático. As potências ocidentais insistiam no reconhecimento, tão-só das liberdades individuais clássicas, protetoras da pessoa humana contra os abu-

${ }^{19}$ Os direitos humanos de primeira geração - Liberdades Civis e Política - representam a emancipação histórica do indivíduo perante os grupos sociais aos quais ele sempre se submeteu: a família, o estamento, as organizações religiosas. As declarações de direitos norte-americanas, juntamente com a Declaração Francesa de 1789 foram as expressões burguesas dos direitos de liberdade e garantia de igualdade formal. A segunda geração de direitos humanos se caracteriza pela imposição de uma ação positiva e intervencionista do Estado para garantir a efetivação de direitos sociais, econômicos e culturais. A Constituição Francesa de 1848 reconheceu algumas exigências econômicas e sociais, porém, a plena afirmação desses novos direitos humanos veio ocorrer de fato no século XX, com a Constituição Mexicana de 1917 e a Constituição de Weimar na Alemanha de 1919. A terceira geração de direitos humanos corresponde ao reconhecimento dos direitos coletivos e difusos - Direitos dos Povos de dimensão planetária - direitos de solidariedade - Direito a paz, ao desenvolvimento dos povos, meio ambiente sadio e ecologicamente equilibrado, reconhecidos pela Declaração sobre Direito ao Desenvolvimento (1986), a Declaração sobre Meio Ambiente e Desenvolvimento (1992) e a Declaração de Viena (1993).

${ }^{20}$ Para Flávia Piovesan: "A Declaração Universal de 1948, ao introduzir a concepção contemporânea de direitos humanos, foi o marco de criação do chamado 'Direito Internacional dos Direitos Humanos'. Após a sua adoção, prevaleceu o entendimento de que a Declaração deveria ser 'juridizada' sob a forma de tratado internacional, que fosse juridicamente obrigatório e vinculante no âmbito do Direito Internacional.” PIOVESAN, Flávia. Proteção internacional dos direitos econômicos, sociais e culturais. In: SARLET, Ingo Wolfgang. Direitos fundamentais sociais: estudos de direito constitucional, internacional e comparado. Rio de Janeiro: Renovar, 2003. p.243. 
sos e interferências dos órgãos estatais na vida privada. Já os países do bloco comunista e os jovens países africanos preferiram pôr em destaque os direitos sociais e econômicos, que têm por objeto políticas públicas de apoio aos grupos ou classes desfavorecidas, deixando na sombra as liberdades individuais. Decidiu-se, por isso, separar essas duas séries de direitos em tratados distintos. ${ }^{21}$

Entretanto, essa divisão em dois tratados é meramente formal, uma vez que a concepção contemporânea de direitos humanos caracteriza-se pelos processos de universalização e internacionalização desses direitos, compreendidos sob o prisma de sua indivisibilidade.

Segundo Flávia Piovesan, em face da indivisibilidade dos direitos humanos, há de ser definitivamente afastada a equivocada noção de que uma classe de direitos (a dos direitos civis e políticos) merece inteiro reconhecimento e respeito, enquanto outra classe de direitos (a dos direitos sociais, econômicos e culturais), ao revés, não merece qualquer observância. São eles autênticos e verdadeiros direitos fundamentais, acionáveis, exigíveis e demandam séria e responsável observância. Por isso devem ser reivindicados como direitos e não como caridade, generosidade ou compaixão. ${ }^{22}$

Cabe aqui apontar alguns artigos do Pacto Internacional sobre Direitos Econômicos, Sociais e Culturais a fim de demonstrar como o direito ao desenvolvimento foi inserido no rol dos direitos humanos.

$\mathrm{O}$ artigo $6^{\circ}$ do Pacto Internacional sobre Direitos Econômicos, Sociais e Culturais reconhece o direito ao trabalho "[...] que compreende o direito de toda

${ }^{21}$ COMPARATO, Fábio Konder. A afirmação histórica dos direitos humanos. 3. ed. rev. e ampl. São Paulo: Saraiva, 2003. p. 276.

${ }^{22}$ Além disso, na mesma linha do que defende Amartya Sen ao tratar das liberdades humanas, em razão dessa "indivisibilidade dos direitos humanos, a violação aos direitos econômicos, sociais e culturais propicia a violação aos direitos civis e políticos, eis que a vulnerabilidade econômico-social leva à vulnerabilidade dos direitos civis e políticos”. PIOVESAN, Flávia. Proteção internacional dos direitos econômicos, sociais e culturais. In: SARLET, Ingo Wolfgang. Direitos fundamentais sociais: estudos de direito constitucional, internacional e comparado. Rio de Janeiro: Renovar, 2003.p. 240-241. 
pessoa de ter a possibilidade de ganhar a vida mediante um trabalho livremente escolhido ou aceito" e transfere aos Estados a responsabilidade de garantir tal direito e de implementar medidas que assegurem "um desenvolvimento econômico, social e cultural constante e o pleno emprego produtivo em condições que salvaguardem aos indivíduos o gozo das liberdades políticas e econômicas fundamentais."

Interessante o comentário do Prof. Fábio Konder Comparato ao referido artigo, o qual dispõe que:

O direito ao trabalho implica, de um lado, o direito de livre exploração de uma atividade econômica independente; individual ou societária; de outro, o direito a exercer um trabalho assalariado, no quadro de uma organização empresarial. No primeiro caso, o direito ao trabalho fundamenta não apenas a liberdade de exercer livremente uma atividade empresarial, mas também o direito à ocupação de terras inexploradas ou mal exploradas, para o exercício de uma atividade agrícola. Neste sentido, o direito assegurado neste artigo do Pacto representa uma das justificativas da política de reforma agrária para a realização de assentamentos agrícolas. ${ }^{23}$

$\mathrm{Na}$ linha do que defende Ignacy Sachs, ${ }^{24}$ a fim de que o desenvolvimento possa permitir que cada indivíduo revele suas capacidades, seus talentos e sua imaginação na busca da autorrealização, mediante esforços coletivos e individuais, combinação de trabalho autônomo e heterônomo e de tempo gasto em atividades não econômicas, o artigo $7^{\circ}$ do Pacto Internacional sobre Direitos Econômicos, Sociais e Culturais prevê:

O direito de toda pessoa de gozar de condições de trabalho justas e favoráveis, que assegurem especialmente: a) uma remuneração que proporcione, no mínimo, a todos os trabalhadores: i) um salário eqüitativo e uma remuneração igual por um trabalho de igual valor, sem qualquer distinção; em particular, as mulheres deverão ter a garantia de condições de trabalho não inferiores às dos homens e receber a mesma remuneração que ele por trabalho igual;

${ }^{23}$ COMPARATO, Fábio Konder. A afirmação histórica dos direitos humanos. 3.ed. rev. e ampl. São Paulo: Saraiva, 2003. p. 343.

${ }^{24}$ COMPARATO, Fábio Konder. A afirmação histórica dos direitos humanos. 3.ed. rev. e ampl. São Paulo: Saraiva, 2003. p. 9-10. 
ii) uma existência decente para eles e suas famílias, em conformidade com as disposições do presente Pacto. b) a segurança e a higiene no trabalho; c) igual oportunidade para todos de serem promovidos, em seu trabalho, á categoria superior que lhes corresponda, sem outras considerações que as de tempo de trabalho e capacidade; d) o descanso, o lazer, a limitação razoável das horas de trabalho e férias periódicas remuneradas.

\section{$\mathrm{O}$ artigo $10^{\circ}$ estabelece que os Estados reconheçam que:}

Deve-se conceder à família, que é o elemento natural e fundamental da sociedade, a mais ampla proteção e assistência possíveis, especialmente para a sua constituição e enquanto ela for responsável pela criação e educação dos filhos. [...]. e devem adotar medidas especiais de proteção e de assistência em prol de todas as crianças e adolescentes, sem distinção por motivo de filiação ou qualquer outra condição. Devem-se proteger as crianças e adolescentes contra a exploração econômica e social.

E por fim, no artigo 11, os Estados Partes do referido Pacto:

[...] reconhecem o direito de toda pessoa em nível de vida adequado para si próprio e sua família, inclusive à alimentação, vestimenta e moradia adequadas, assim como a uma melhoria contínua de suas condições de vida. Os Estados Partes tomarão medidas apropriadas para assegurar a consecução desse direito, reconhecendo, nesse sentido, a importância essencial da cooperação internacional fundada no livre consentimento.

2. Os Estados Partes do presente pacto, reconhecendo o direito fundamental de toda pessoa de estar protegida contra a fome, adotarão, individualmente e mediante cooperação internacional, as medidas, inclusive programas concretos, que se façam necessárias para: a) melhorar os métodos de produção, conservação e distribuição de gêneros alimentícios pela plena utilização dos conhecimentos técnicos e científicos, pela difusão de princípios de educação nutricional e pelo aperfeiçoamento ou reforma dos regimes agrários, de maneira que se assegurem a exploração e a utilização mais eficazes dos recursos naturais; b) Assegurar uma repartição eqüitativa dos recursos alimentícios mundiais em relação às necessidades, levando-se em conta os problemas tanto dos países importadores quanto dos exportadores de gêneros alimentícios. 
Entende-se que o artigo acima transcrito seja claro e não necessite de maiores comentários, entretanto, vale ressaltar a importância de políticas públicas voltadas para a instituição de uma renda mínima para as famílias e para os indivíduos. Além disso, o artigo reitera a questão da fome, da questão agrária e da cooperação internacional para realização de medidas para erradicação da fome.

Para finalizar a análise do Pacto Internacional sobre Direitos Econômicos, Sociais e Culturais, é importante realçar a realização plena dos direitos humanos como direitos positivos universais e a importância do Pacto e de outros instrumentos internacionais que:

[...] acabaram por alargar as tarefas do Estado, incorporando fins econômico-sociais positivamente vinculantes das instâncias de regulação jurídica. A política deixa de ser concebida como um domínio juridicamente livre e desvinculado. Os domínios da política passam a sofrer limites, mas também imposições, por meio de um projeto material vinculativo. [...] os tratados internacionais apreciados têm como tarefa juridificar o domínio político, impondo deveres aos Estados e enunciando direitos essenciais à proteção da dignidade humana. ${ }^{25}$

Outro instrumento internacional que possui relevância com o temática do desenvolvimento é a Declaração sobre o Direito ao Desenvolvimento de $1986,{ }^{26} \mathrm{a}$ qual em seu preâmbulo reconhece que:

[...] o desenvolvimento é um processo econômico, social, cultural e político abrangente, que visa ao constante incremento do bem-estar de toda a população e de todos os indivíduos com base em sua participação ativa, livre e significativa no desenvolvimento e na distribuição justa dos benefícios daí resultantes e que a pessoa humana é o sujeito central do processo de desenvolvimento e que essa política de desenvolvimento deveria assim fazer do ser humano o principal participante e beneficiário do desenvolvimento; e por fim

${ }^{25}$ PIOVESAN, Flávia. Proteção internacional dos direitos econômicos, sociais e culturais. In: SARLET, Ingo Wolfgang. Direitos fundamentais sociais: estudos de direito constitucional, internacional e comparado. Rio de Janeiro: Renovar, 2003. p. 249.

${ }^{26}$ Adotada pela ORGANIZAÇÃO DAS NAÇÕES UNIDAS. Assembléia geral das Nações Unidas. Resolução n.41/128 de 4 de dezembro de 1986. 
confirma que o direito ao desenvolvimento é um direito humano inalienável e que a igualdade de oportunidade para o desenvolvimento é uma prerrogativa tanto das nações quanto dos indivíduos que compõem as nações (grifo nosso).

A Declaração sobre o Direito ao Desenvolvimento de 1986 foi endossada pela Declaração de Viena ${ }^{27}$ (1993), a qual reconheceu os direitos coletivos e difusos, dentre os quais o direito ao meio ambiente sadio e ecologicamente equilibrado e o direito ao desenvolvimento dos povos, realçando a inter-relação entre democracia, desenvolvimento e direitos humanos.

Conforme exposto acima, o conceito de direito ao desenvolvimento foi sendo construído e se tornando mais complexo. Passou a abordar aspectos políticos, econômicos, culturais, sociais e, por fim, agregou a variável da sustentabilidade.

A Declaração sobre Meio Ambiente e Desenvolvimento ${ }^{28}$ (Rio de Janeiro, 1992) propõe ao mundo soluções por meio do desenvolvimento sustentável. No que tange às questões agrárias:

[...] fazia-se urgente reajustar a política agrícola, ambiental e macroeconômica. Devia-se passar de uma agricultura tradicional a uma agricultura sustentável. O principal objetivo seria aumentar a produção de alimentos e melhorar a segurança alimentar. Entre outras, deveriam ser tomadas medidas orientadas às grandes transformações sociais, como são a produção de alimentos para os mercados, geração de empregos para combater a pobreza e fundamentalmente a ordenação dos recursos naturais e a proteção do meio ambiente. ${ }^{29}$

Na Declaração sobre Meio Ambiente e Desenvolvimento (Rio de Janeiro, 1992) foram enumerados princípios a serem seguidos pelos Estados, dos quais são relevantes para o presente texto:

${ }^{27}$ Adotada consensualmente, em plenário, pela CONFERÊNCIA MUNDIAL DOS DIREITOS HUMANOS, 25 de junho de 1993.

${ }^{28}$ Os problemas existentes e, que se agravavam, (tais como, as desigualdades econômicas, o crescimento populacional, a fome, o desemprego e a crescente dívida externa de países em desenvolvimento) fizeram com que a humanidade começasse a se questionar a respeito do desenvolvimento que se pretendia.

${ }^{29}$ ZELEDÓN, Ricardo Zeledon. Desarrollo. In: Paraná: Juruá, 2001. p.151. . Derecho agrario y derechos humanos. 
Princípio 3 - O direito ao desenvolvimento deve ser exercido de modo a permitir que sejam atendidas eqüitativamente as necessidades de gerações presentes e futuras. ${ }^{30}$

Princípio 4 - Para alcançar o desenvolvimento sustentável, a proteção ambiental deve constituir parte integrante do processo de desenvolvimento, ${ }^{31}$ e não pode ser considerada isoladamente deste;

Princípio 5 - Todos os Estados e todos os indivíduos, como requisito indispensável para o desenvolvimento sustentável, devem cooperar na tarefa essencial de erradicar a pobreza, de forma a reduzir as disparidades nos padrões de vida e melhor atender as necessidades da maioria da população do mundo.

Princípio 11 - Os estados devem adotar legislação ambiental eficaz. Padrões ambientais e objetivos e prioridades em matéria de ordenação do meio ambiente devem refletir o contexto ambiental e de desenvolvimento a que se aplicam. Padrões utilizados por alguns países podem resultar inadequados para outros, em especial países em desenvolvimento, acarretando custos sociais e econômicos injustificados.

Princípio 12 - Os Estados devem cooperar para o estabelecimento de um sistema econômico internacional aberto e favorável, propício ao crescimento econômico e ao desenvolvimento sustentável em todos os países, de modo a possibilitar o tratamento mais adequado dos problemas da degradação ambiental. Medidas de política comercial

${ }^{30}$ A grande dificuldade está na identificação das necessidades e na avaliação dos interesses das gerações futuras. Para uma leitura mais aprofundada acerca da incomensurabilidade intergeracional de valores, ver MONTIBELLER FILHO, Gilberto. $O$ mito do desenvolvimento sustentável: meio ambiente e custos sociais no moderno sistema produtor de mercadorias. 3. ed. Florianópolis: UFSC, 2008.

${ }^{31}$ Segundo Roberto de Campos Andrade, "A nova qualidade do modelo de desenvolvimento proposto depende substancialmente de implementação de políticas públicas compatíveis com os critérios de sustentabilidade. Assim políticas voltadas ao fomento industrial não podem deixar de considerar a variável ambiental. As fontes de energia utilizadas devem ser compatíveis com a capacidade de suporte dos ecossistemas. Os mecanismos de financiamento devem priorizar a utilização de tecnologias limpas. Deve-se analisar ainda o impacto social da política [...] que pode ter um efeito pernicioso sobre o ambiente”. Desenvolvimento Sustentável e Direito Internacional. In: AMARAL JUNIOR, A.(Org.). Direito internacional e desenvolvimento. Barueri: Manole, 2005. p. 360. 
para propósitos ambientais não devem constituir-se em meios para a imposição de discriminações arbitrárias ou injustificáveis ou em barreiras disfarçadas ao comércio internacional. Devem ser evitadas ações unilaterais para o tratamento de questões ambientais fora da jurisdição do país importador. Medidas destinadas a tratar de problemas ambientais transfronteiriços ou globais devem, na medida do possível, basear-se em um consenso internacional. ${ }^{32}$

Princípio 20-Asmulheres desempenham papelfundamental na gestão do meio-ambiente e no desenvolvimento. Sua participação plena é, portanto, essencial para a promoção do desenvolvimento sustentável. ${ }^{33}$ (grifo nosso)

E o que é então esse "desenvolvimento sustentável”?

O desenvolvimento não está mais relacionado apenas a crescimento econômico, foi aperfeiçoado e ampliado para abarcar outros aspectos da vida humana e garantir que todos os outros direitos e liberdades possam ser plenamente realizados. E com esse qualificativo "sustentável" acresce-se que o desenvolvimento

${ }^{32}$ A Organização Mundial do Comércio possui dois acordos multilaterais que procuram regular a aplicação de barreiras fitossanitárias (Acordo sobre a Aplicação de Medidas Sanitárias e Fitossanitárias) e a imposição de barreiras técnicas (Acordo sobre Barreiras Técnicas ao Comércio). Esses dois acordos visam assegurar que os países membros da OMC não se utilizem de medidas arbitrárias ou de barreiras técnicas que possam distorcer o comércio internacional sob a disfarçada justificativa de proteção ambiental. Além disso, o artigo XX do GATT94 prevê exceções gerais a um dos princípios fixados no GATT94 (restrições quantitativas) e a imposição de medidas, "desde que essas não sejam aplicadas de forma a constituir quer um meio de discriminação arbitrária, ou injustificada, entre os países onde existem as mesmas condições, quer uma restrição disfarçada ao comércio internacional,

(b) necessárias à proteção da saúde e da vida das pessoas e dos animais e à preservação dos vegetais; [... ]

(g) relativas à conservação dos recursos naturais esgotáveis, se tais medidas forem aplicadas conjuntamente com restrições à produção ou ao consumo nacionais.

${ }^{33}$ As mulheres desempenham papel importante nas questões ambientais e do desenvolvimento. Primeiramente, porque muitas mulheres são chefes de famílias mono parentais e acabam por manter suas famílias com o trabalho desenvolvido junto ao meio agrário. Além disso, já foi provado que, em algumas partes do mundo, as meninas e mulheres têm menos acesso ao alimento do que os meninos e os homens. Para uma análise criteriosa, ver Asbjorn Eide, A realização dos direitos econômicos, sociais e culturais - o direito à alimentação adequada e a estar livre da fome" In: VALENTE, Flávio Luiz Schieck (Org.). Direito humano à alimentação: desafios e conquistas. São Paulo: Cortez, 2002. 
precisa ser ecologicamente sustentável. ${ }^{34}$

Segundo Ignacy Sachs, o desenvolvimento sustentável seria composto por oito dimensões: social, cultural, ecológica, ambiental, territorial, econômica, política nacional e política internacional. Uma abordagem clara acerca das dimensões da sustentabilidade foi apresentada por Leandro Pereira Morais e Adriano Borges Ferreira Costa, a qual é transcrita abaixo para melhor compreensão:

ecológica (estoque e uso de recursos naturais utilizados na produção e no consumo);

ambiental (capacidade da natureza de absorver e recuperarse das agressões);

demográfica (à luz das duas anteriores, analisar o impacto da dinâmica demográfica);

cultural (criação/ preservação de valores e práticas que induzam novos padrões de integração nacional, regional e local);

social (melhoria da qualidade de vida e justiça distributiva);

política (possibilidades de construção participativa da cidadania e de um novo projeto de desenvolvimento); e institucional (como todos esses aspectos se refletem na construção de novas institucionalidades sociais, políticas e econômicas). ${ }^{35}$

No âmbito do Direito Internacional, a fim de indicar os princípios fundamentais que constituem o cerne do conceito de desenvolvimento sustentável, a International Law Association (ILA) elaborou a Declaração de Princípios de Nova Deli de Direito Internacional sobre Desenvolvimento Sustentável:

1. Princípio da obrigação dos Estados em assegurar o uso sustentável dos recursos naturais;

2. Princípio da equidade e da erradicação da pobreza;

\footnotetext{
${ }^{34}$ Para José Eli da Veiga, não se trata de um aperfeiçoamento da noção de desenvolvimento, ao contrário, a qualificação do desenvolvimento como sustentável reconhece a necessidade de sua negação/superação, reflete o crescente esgotamento de um dos principais valores dos tempos modernos. VEIGA, José Eli da. Desenvolvimento sustentável: o desafio do século xxi. 3. ed. [Rio de Janeiro]:Garamond, 2008. p.192.

${ }^{35}$ MORAIS, Leandro Pereira; COSTA, Adriano Borges Ferreira. Por novos paradigmas de produção e consumo. Le monde diplomatique Brasil, São Paulo, nov. 2009, p.14-15.
} 
3. Princípio de responsabilidades comuns, mas diferenciadas;

4. Princípio da abordagem preventiva com relação à saúde humana, recursos naturais e ecossistemas;

5. Princípio da participação pública e do acesso à informação e à justiça;

6. Princípio da boa governança; e

7. Princípio da integração e da interdependência de objetivos sociais, econômicos e ambientais. ${ }^{36}$

Por fim, com o objetivo de fornecer maiores detalhes acerca do conceito de desenvolvimento sustentável, passa-se a listar os principais objetivos das políticas ambientais e desenvolvimentistas que derivam desse conceito, os quais foram apresentados no relatório da Comissão Brundtland:

(1) retomar o crescimento; (2) alterar a qualidade do desenvolvimento; (3) atender às necessidades essenciais de emprego, alimentação, energia, água e saneamento; (4) manter um nível populacional sustentável; (5) conservar e melhorar a base de recursos; (6) reorientar a tecnologia e administrar riscos; e (7) incluir o meio ambiente e a economia no processo de decisão. ${ }^{37}$

Para concluir, o direito ao desenvolvimento evoluiu e passou a abarcar outras dimensões além da meramente econômica. Ao ser incorporado na normativa dos direitos humanos, o direito ao desenvolvimento assumiu também aspectos sociais, políticos, culturais e, posteriormente, em decorrência da crescente preocupação com a questão ambiental e o esgotamento dos recursos naturais, ao direito ao desenvolvimento foi acrescida a variável sustentabilidade. Esse qualificativo visa aliar crescimento econômico, inclusão social e sustentabilidade ambiental.

Essa construção gradual de um regime jurídico do desenvolvimento não se encontra apenas no Direito Internacional Público. Esse regime jurídico se dá mediante a inter-relação do Direito Internacional com o direito interno. Trata-se de

\footnotetext{
${ }^{36}$ ANDRADE, Roberto de Campos. Desenvolvimento sustentável e direito internacional. In: AMARAL JUNIOR, A.(Org.). Direito internacional e desenvolvimento. Barueri: Manole, 2005. p. 366-371.

${ }^{37}$ ANDRADE, Roberto de Campos. Desenvolvimento sustentável e direito internacional. In: AMARAL JUNIOR, A. (Org.). Direito internacional e desenvolvimento. Barueri: Manole, 2005. p. 361.
} 
um direito de antecipação e de finalidade, que pensa a sociedade futura (gerações presente e futura) e, por isso mesmo, possui regras positivas e prospectivas.

O Brasil, na qualidade de signatário dos tratados e acordos internacionais acima e tendo internalizado os mesmos no ordenamento nacional, encontra-se vinculado a tais instrumentos e deve observá-los quando da elaboração de políticas públicas.

\section{A formulação e implementação de políticas públicas pertinentes ao direito ao desenvolvimento sustentável}

Antes de serem apresentadas algumas políticas públicas relacionadas ao desenvolvimento sustentável, serão brevemente discutidas as dimensões jurídicas das políticas públicas na realização dos direitos humanos.

A partir do Pacto Internacional sobre Direitos Econômicos, Sociais e Culturais, a posição do Estado passou do polo passivo para o polo ativo da relação jurídica. Anteriormente, cabia ao Estado manter-se inerte e não violar os direitos e liberdades civis e políticas dos cidadãos. A partir de meados do século XX, o Estado passa a atuar ativamente na elaboração de políticas públicas ${ }^{38}$ ou programas de ação governamental para implementação e efetivação dos direitos humanos de conteúdo econômico, social e cultural.

Como bem ensina Fábio Konder Comparato:

Uma política pública não é um ato isolado nem, menos ainda, a abstenção de praticar determinados atos. Ela

\footnotetext{
${ }^{38}$ Segundo Clóvis Zimmermann, Políticas Públicas na realização dos direitos humanos e, em especial dos direitos econômicos, sociais e culturais, vem sendo enfatizada em muitas das análises sobre exigibilidade (perante o Estado) e justiciabilidade (perante os tribunais de justiça) dos direitos humanos. Por políticas públicas define-se o conjunto de regras, planos, estratégias, programas, projetos ou omissões, assumidos parcial ou totalmente por órgãos governamentais, visando à realização dos direitos humanos. As políticas públicas e a exigibilidade do direito humano à alimentação. PIOVESAN, Flávia; CONTI, Irio Luiz (Coord.). Direito humano à alimentação adequada. Rio de Janeiro: Lumen Juris, 2007.
} 
consiste numa atividade, conceito técnico elaborado pela mais recente teoria jurídica. Trata-se, com efeito, de uma série de atos, do mais variado tipo, unificados pela comunhão de escopo e organizados num programa de longo prazo. ${ }^{39}$

Assim, os Estados se viram obrigados a criar um "modelo jurídico próprio para a legitimação e promoção de suas ações", ou seja, um “direito das políticas públicas”, que na realidade é um "direito ordenador do presente rumo às transformações almejadas". E é exatamente por isso que esse direito acaba por "aglutinar normas de regulação de condutas, de organização, de planificação, de conceituação de diretrizes, de fixação de metas" ${ }^{40}$

Para uma definição precisa sobre políticas públicas, utiliza-se o ensinamento de Patrícia Helen Massa-Arzabe:

\begin{abstract}
Políticas públicas, sob o prisma da atividade, são conjuntos de programas de ação governamental estáveis no tempo, racionalmente moldadas, implantadas e avaliadas, dirigidas à realização de direitos e de objetivos sociais juridicamente relevantes, notadamente plasmados na distribuição e redistribuição de bens e posições que concretizem oportunidades para cada pessoa viver com dignidade e exercer seus direitos, assegurando-lhes recursos e condições para a ação, assim como a liberdade de escolha para fazerem uso desses recursos (não se confundem, portanto, com práticas e programas desenvolvidos em espaço curto de tempo ou postos para satisfazer ânimos pré-eleitorais).
\end{abstract}

Por fim, cabe ainda destacar que a realização de políticas públicas pressupõe a relação combinada entre Estado e sociedade civil (agentes econômicos, organizações civis e particulares), dando real significado à democracia participativa. $\mathrm{Na}$ esfera estatal, o Poder Executivo desempenha um papel central na implementação das políticas públicas. Conforme enfatiza Clóvis Zimmermann:

\footnotetext{
${ }^{39}$ COMPARATO, Fábio Konder. A afirmação histórica dos direitos humanos. 3.ed. rev. e ampl. São Paulo: Saraiva, 2003. p. 334.

${ }^{40}$ MASSA-ARZABE, Patrícia Helena. Dimensão jurídica das políticas públicas. In:. BUCCI, Maria Paula Dallari (Org.). Políticas públicas: reflexões sobre o conceito jurídico. São Paulo: Saraiva, 2006.
} 
Ele deve assumir sua responsabilidade no tocante à formulação de estratégias claras de implementação dos direitos econômicos, sociais e culturais. Um dos papéis do Executivo é fomentar um enfoque baseado na participação de todos os cidadãos, aproveitando as suas capacidades especializadas com vistas a facilitar o uso eficiente de recursos. ${ }^{41}$ Por outro lado, o Poder Judiciário 'O Poder Judiciário não tem como tarefa projetar políticas públicas, mas sim confrontar as políticas assumidas com os padrões jurídicos aplicáveis e, no caso de haver divergências, reenviar a questão aos poderes pertinentes para que eles ajustem sua atividade.' Ou seja, a ação jurídica é, em maior escala, aplicável na existência de políticas públicas compatíveis aos direitos, cabendo ao Judiciário a tarefa de exigir mudanças e ajustes nas mesmas em caso de violações.. ${ }^{42}$

A partir da compreensão do que sejam políticas públicas e dos atores que participam de sua formulação, implementação e avaliação, passa-se a apresentar, a título de exemplo, algumas políticas públicas de sustentabilidade relacionadas à defesa do meio ambiente, segurança alimentar e desenvolvimento sustentável.

Em relação à defesa do meio ambiente e às mudanças climáticas, o Brasil possui um caráter singular, de um lado, a matriz energética brasileira é uma das mais avançadas no uso das fontes renováveis (seja mediante o uso de hidrelétricas seja no uso de combustíveis líquidos), de outro, o desmatamento é cada vez mais crescente.

E a maior fonte brasileira de emissão de gases de efeito estufa é o desmatamento. Atualmente, o país contribui com cerca de $4 \%$ das emissões globais - 75\% delas são originárias da mudança de uso do solo (ou seja, desmatamento) e $25 \%$ da queima de combustíveis fósseis. Diante dessa peculiaridade, o desafio do país é duplo: as ações de combate ao desmatamento e de redução de emissões de gases estufa estão inter-relacionadas, caminham juntas. ${ }^{43}$

${ }^{41}$ ZIMMERMANN, Clóvis. As políticas públicas e a exigibilidade do direito humano à alimentação. In: PIOVESAN, Flávia; CONTI, Irio Luiz (Coord.). Direito humano à alimentação adequada. Rio de Janeiro: Lumen Juris, 2007.

42 ZIMMERMANN, Clóvis. As políticas públicas e a exigibilidade do direito humano à alimentação. In: PIOVESAN, Flávia; CONTI, Irio Luiz (Coord.). Direito humano à alimentação adequada. Rio de Janeiro: Lumen Juris, 2007.

${ }^{43}$ RELATÓRIO Brundtland e a sustentabilidade: mudanças climáticas. Brasília, 2011. Disponível em: <http://www.mudancasclimaticas.andi.org.br/node/91>. Acesso em: 11 mar. 2011. 


\section{O governo federal através do Plano de Ação para Prevenção e Controle}

do Desmatamento da Amazônia Legal ${ }^{44}$ apresentou um conjunto de ações estratégicas, consideradas prioritárias por sua relevância para a contenção do desmatamento na Amazônia Legal, bem como para a viabilização de estratégias alternativas de proteção e uso sustentável da floresta. O referido Plano de Ação prevê (i) fomento às atividades sustentáveis, mediante o aperfeiçoamento de instrumentos de financiamento e créditos existentes, que utilizam recursos públicos para promover atividades produtivas sustentáveis e desestimular o desmatamento ilegal; ${ }^{45}$ (ii) desenvolver e implementar o programa de capacitação, formação e divulgação do manejo florestal sustentável; (iii) apoiar as comunidades extrativistas e indígenas; (iv) fomento ao ecoturismo; (v) implantar e consolidar polos pioneiros de produção familiar sustentável; (vi) apoiar o desenvolvimento sustentável da cadeia produtiva de madeira e móveis; (vii) implementar ações para uma política agrícola sustentável para a Amazônia legal; e (viii) adotar como exigência básica para os produtores rurais contemplados nos programas e ações do Ministério da Agricultura, da Pecuária e do Abastecimento o cumprimento da legislação ambiental.

Na política pública citada, o Ministério do Meio Ambiente atuou como agente de uma agenda transversal sustentável em várias áreas do governo, refletindo nas ações do Ministério da Agricultura, da Pecuária e do Abastecimento, no Ministério do Turismo e nos órgãos de fomento (ex.: BNDES), passando a ser o foco indutor e alimentador do modelo geral planejado pelo governo. Essa transver-

\footnotetext{
${ }^{44}$ BRASIL. Presidência da República. Casa Civil. Grupo permanente de trabalho interministerial para a redução dos índices de desmatamento da Amazônia Legal Decreto de 3 de julho de 2003. Disponível em: <http://www.planalto.gov.br/ccivil_03/dnn/2003/ Dnn9922.htm >. Acesso em: Acesso em: 11 mar. 2011.

${ }^{45}$ De acordo com o site http://www.mudancasclimaticas.andi.org.br: O Banco Central publicou uma Resolução proibindo os bancos públicos de conceder créditos e financiamentos no bioma amazônico para produtores de regiões que não possuem legalização ambiental. A bancada ruralista do Congresso e alguns governos estaduais da Amazônia criticaram a medida. O ministro Carlos Minc declarou: "Antes, o dinheiro público estava financiando o desmatamento".
} 
salidade $^{46}$ vem de acordo com o que preconizam Bruno Pagnoccheschi e Maristela Bernardo, "O pressuposto é o de que políticas ambientais, mesmo quando formuladas no setor ambiental, só se realizam e efetivam por meio das demais políticas, se estiverem nelas expressas desde sua concepção" ${ }^{47}$

No que tange à segurança alimentar, ${ }^{48}$ não cabe no presente texto discorrer sobre os compromissos assumidos pelo Brasil no âmbito da FAO ${ }^{49}$ (tais como, Declaração de Roma sobre Segurança Alimentar e o Plano de Ação da Cúpula Mundial), nem abordar a construção e a relevância do direito à alimentação. Apenas, pretende-se realçar as obrigações nacionais e internacionais do Estado no âmbito do direito à alimentação, a fim de verificar se tais obrigações têm sido observadas nas políticas públicas de segurança alimentar no Brasil.

Segundo Asbjorn Eide:

Os Estados devem, em um primeiro nível, respeitar os recursos produtivos de propriedade do indivíduo, sua liberdade de achar o emprego de sua preferência, para fazer o melhor uso de seus conhecimentos e respeitar a

\footnotetext{
46 "A transversalidade é talvez, nesse momento da política ambiental brasileira, o conceito com maior carga de significados e expectativas para o futuro. De um lado, o fato de ter sido colocado claramente na pauta do governo, estabelece uma inequívoca rota de avanço que contempla reivindicações históricas dos segmentos da sociedade mais comprometidos e atuantes na questão ambiental, em especial as organizações não-governamentais e a comunidade científica. Para eles, a localização do setor ambiental público sempre foi um tema essencial, justamente por desvendar um problema de fundo para a viabilidade de um modelo de desenvolvimento sustentável”. Bruno Pagnoccheschi e Maristela Bernardo. Política Ambiental no Brasil. STEINBERGER, Marília (Org.). Território, ambiente e políticas públicas espaciais. Brasília: LGE, 2006. p.122

${ }^{47}$ STEINBERGER, Marília (Org.). Território, ambiente e políticas públicas espaciais. Brasília: LGE, 2006, p.120.

${ }^{48}$ A segurança alimentar é definida, corretamente, como o acesso de todos, continuamente, ao alimento necessário para uma vida sadia e ativa. Alcançar a segurança alimentar domiciliar significa assegurar que há alimento suficiente na localidade em questão, que o suprimento é relativamente estável, e que todos precisem de alimento naquela área tenham a capacidade de obtê-lo, para usufruir uma vida saudável e produtiva. Asbjorn Eide. "realização dos direitos econômicos, sociais e culturais - o direito à alimentação adequada e a estar livre da fome. In: VALENTE, Flávio Luiz Schieck (Org.). Direito humano à alimentação: desafios e conquistas. São Paulo: Cortez, 2002. p.228.

${ }^{49}$ Organização das Nações Unidas para Agricultura e Alimentação.
} 
sua liberdade de agir e de utilizar os recursos necessários para satisfazer as suas próprias necessidades. Em um nível secundário, as obrigações do Estado requerem proteção ativa contra atores mais assertivos ou agressivos, ou interesses econômicos mais poderosos, tais como proteção contra fraude; contra comportamento antiético no comércio ou em relações contratuais; contra a comercialização ou dumping de produtos inseguros ou perigosos. Em um nível terciário, o Estado deve adotar medidas para melhorar práticas de produção, conservação e distribuição de alimentos fazendo uso de todo o conhecimento técnico e científico disponível e pelo desenvolvimento ou reforma dos sistemas agrários. ${ }^{50}$ (grifo nosso)

Diversas são as políticas públicas relacionadas à segurança alimentar no Brasil: Projeto Fome Zero, Programa de Garantia de Renda Mínima, "Cheque Cidadão" do governo do Rio de Janeiro e "Renda Cidadã" do Estado de Goiás. ${ }^{51}$ Tais programas versam primordialmente a respeito da distribuição de alimento, tendo como finalidade subsidiar a renda das famílias para poder se alimentar adequadamente. Entretanto, tais políticas não tratam das causas estruturais da fome e da exclusão social. Os compromissos assumidos pelo Brasil requerem a realização de uma significativa reforma agrária que garanta uma estrutura fundiária mais igualitária, a criação de políticas de geração de emprego e renda e o desenvolvimento de uma política agrícola de incentivo efetivo à agricultura familiar, mediante financiamento e apoio técnico.

$\mathrm{Na}$ esfera internacional, o governo brasileiro tem defendido "que a comunidade internacional estabeleça uma verdadeira política pública mundial da alimentação e de agricultura”. Para isso, foi celebrada uma "Parceria Global para a Agricultura, a Segurança Alimentar e a Nutrição" e foi criada a partir do Comitê de Segurança Alimentar da FAO:

\footnotetext{
${ }^{50}$ A realização dos direitos econômicos, sociais e culturais - o direito à alimentação adequada e a estar livre da fome. In: VALENTE, Flávio Luiz Schieck (Org.). Direito humano à alimentação: desafios e conquistas. São Paulo: Cortez, 2002.p. 225-226.

${ }^{51}$ Exemplos citados e analisados no texto de José Graziano da Silva, Walter Belik e Maya Takagi, O que o Brasil pode fazer para combater a fome.SILVA, José Graziano da; BELIK, Walte; TAKAGI, Maya Takagi (Org.). Combate à fome è à pobreza rural: Instituto Cidadania, 2002. p. 131-151.
} 
A assembléia Mundial da Segurança Alimentar que reunirá representantes dos países da ONU, associações profissionais e de camponeses, empresas e ONGs com a missão de coordenar diversas posições, formular e legitimar estratégias comuns para a segurança alimentar no âmbito da economia, das finanças, do comércio e do meio ambiente. Seu desafio será o cumprimento dos compromissos assumidos e a coerência das ações internacionais. ${ }^{52}$

Conforme artigo conjunto do Ministro do Desenvolvimento Agrário do Brasil e do Ministro da Alimentação, Agricultura e Pesca da França publicado ${ }^{53}$ recentemente, existem três temas cruciais que precisam ser enfrentados no cenário internacional em relação à agricultura e segurança alimentar: (i) a volatilidade dos preços dos alimentos no mercado mundial que afeta particularmente a agricultura familiar; (ii) o reconhecimento da importância do desenvolvimento rural, das políticas integradas de apoio à produção e à segurança alimentar em países em desenvolvimento, da reforma agrária e do ordenamento territorial para fazer frente aos riscos da especulação e do investimento predatório; e (iii) o esforço coletivo à adaptação e à atenuação das mudanças climáticas.

Ainda no cenário internacional e no que tange à volatilidade dos preços dos alimentos no mercado mundial, entende-se que o Brasil deve continuar questionando as práticas distorcidas de alguns países, tais como, subsídios agrícolas e picos tarifários, junto à Organização Mundial do Comércio, uma vez que determinados subsídios, somados a barreiras tarifárias ou não-tarifárias, acabam por levar a uma exportação subsidiada, gerando excesso de oferta no mercado internacional e instabilidade nos preços mundiais. Importante ainda lembrar que os produtos agrícolas da pauta de exportação brasileira são os que mais sofrem com os picos tarifários praticados pelos EUA e pelos países que compõem a Comunidade Europeia, fazendo com que se questione o "comércio justo" preconizado por tais países.

52 CASSEL, Guilherme; MAIRE, Bruno Le. Agricultura e alimentação. Folha de São Paulo, São Paulo, p. A-3, 18 nov. 2009.

${ }^{53}$ CASSEL, Guilherme; MAIRE, Bruno Le. Agricultura e alimentação. Folha de São Paulo,São Paulo, p. A-3, 18 nov. 2009. 


\section{Considerações finais}

O presente trabalho abordou a construção do conceito de desenvolvimento, desde sua concepção economicista como sinônimo de crescimento econômico, passando por uma visão cética de que o desenvolvimento consistia em uma manipulação ideológica até a visão ampliada composta por vários aspectos da vida humana (social, cultural, político) defendida por Amartya Sen, Ignacy Sachs e Celso Furtado.

A partir dessa conceituação do desenvolvimento, procurou-se, através dos pactos, declarações celebrados pelos Estados no âmbito do Direito Internacional Público, demonstrar a consolidação do Direito ao Desenvolvimento e a sua consagração como um direito humano de terceira geração, juntamente com o direito ao meio ambiente sadio e ecologicamente equilibrado.

Posteriormente, tratou-se de caracterizar o que são políticas públicas, seus agentes, a sua relevância para efetivação dos direitos econômicos, sociais e culturais, o papel do Poder Executivo como responsável pelo fomento e implementação das políticas públicas e o papel do Poder Judiciário como responsável por confrontar as políticas assumidas com os padrões jurídicos aplicáveis e pela análise de justiciabilidade e exigibilidade.

Por fim, o trabalho procurou dar uma breve visão a respeito das políticas públicas de sustentabilidade praticadas no Brasil em relação à preservação do meio ambiente, à segurança alimentar e ao desenvolvimento sustentável.

Do exposto, pode-se inferir que as políticas estruturais, tais como geração de emprego, renda mínima para garantia da dignidade humana e reforma agrária equitativa ainda são escassas. Além disso, as políticas públicas de segurança alimentar são tímidas, intermitentes e possuem um caráter de filantropia, limitando-se à distribuição de alimentos.

Em relação às políticas públicas de sustentabilidade que têm como foco o meio ambiente, percebe-se um fortalecimento do Ministério do Meio Ambiente como agente fomentador e formulador, buscando uma transversalidade das ques- 
tões do meio ambiente junto a alguns órgãos do Poder Executivo, a organizações não-governamentais e junto à sociedade civil.

Entretanto, cabe ressaltar que o padrão de consumo voltado para os bens não-essenciais e as formas de produção predatórias atuais têm gerado o agravamento das desigualdades sociais e econômicas. Além disso, não são condizentes com um processo de desenvolvimento sustentável.

Assim, faz-se necessária a participação ativa da sociedade civil e do Estado na formulação de políticas públicas de sustentabilidade que procurem efetivar os direitos econômicos, sociais e culturais, bem como o fomento de novas formas de produção e de consumo voltadas para o desenvolvimento sustentável e que garantam o pleno exercício das liberdades e capacidades humanas.

\section{The construction of the right to development and its application}

\section{Abstract}

This paper presents the historical evolution of the right to development under an international Law perspective and its implementation through public policies. The main objective herein is the analysis of the historical process of construction that leads to the right to development. Initially, the right to development was attached to economic development, however through such process it was enhanced and expanded to guarantee some essential aspects of human life and all its potentialities. Through the analysis of international declarations, such as International Covenant on Economic, Social and Cultural Rights, Declaration on the Right to Development, Rio Declaration on Environment and Development, this paper intended to demonstrate that the sustainable development is a legal principle which resulted from the international consensus and the international legal system of environmental protection. In the second part, this paper examines the legal dimensions of public policies within the implementation of human rights as well as presents the parts that are related to its formulation, application and evaluation. At last the legal principle of sustainable development is analyzed within our 
political, economical and social reality through Brazilian public policies related to environment and food security. The value of this paper is the combination of the legal principle of sustainable development built through international Law and its implementation within public policies and the empirical demonstration of such combination through the evaluation of the rain forest action plan and the public policies on food security in Brazil.

Keywords: Right to development. Human rights. Public policies. Sustainable development.

\section{Referências}

ANDRADE, Roberto de Campos. Desenvolvimento sustentável e direito internacional. In: AMARAL JUNIOR, A.(Org.). Direito internacional $e$ desenvolvimento. Barueri: Manole, 2005. p. 366-371.

BORGES, Daniel Damásio. Ética e economia: fundamentos para uma reaproximação. In: AMARAL JUNIOR, A. (Org.). Direito internacional $e$ desenvolvimento. Barueri: Manole, 2005. p. 1-51.

BRAGA, Antônio Sérgio; MIRANDA, Luiz Camargo (Org.). Comércio e meio ambiente: uma agenda positiva para o desenvolvimento sustentável. Brasília: MMA/SDS, 2002.

CARDIA, Fernando Antonio Amaral. Uma breve introdução à questão do desenvolvimento como tema de direito internacional. In: AMARAL JUNIOR, A.(Org.). Direito internacional e desenvolvimento. Barueri: Manole, 2005. p. 62 et. seq.

CASSEL, Guilherme; MAIRE, Bruno Le. Agricultura e alimentação. Folha de São Paulo, São Paulo, p. A-3,18 nov.2009.

COMPARATO, Fábio Konder. A afirmação histórica dos direitos humanos. 3.ed. rev. e ampl. São Paulo: Saraiva, 2003.

FARIA José Eduardo (Org.). Direito e globalização econômica: implicações e perspectivas. Itaim Bibi, SP, Malheiros, 1996. 
MAGALHÃES, José Carlos de. Direito econômico internacional. Curitiba: Juruá, 2009.

MASSA-ARZABE, Patrícia Helena. Dimensão jurídica das políticas públicas. In: BUCCI, Maria Paula Dallari (Org.). Políticas públicas: reflexões sobre o conceito jurídico. São Paulo: Saraiva, 2006.

MONTIBELLER-FILHO, Gilberto. O mito do desenvolvimento sustentável: meio ambiente e custos sociais no moderno sistema produtor de mercadorias. 3. ed. Florianópolis: UFSC, 2008.

MORAIS, Leandro Pereira; COSTA, Adriano Borges Ferreira. Por novos paradigmas de produção e consumo. Le Monde Diplomatique Brasil, São Paulo, p. 14-15, nov. 2009.

PIOVESAN, Flávia; CONTI, Irio Luiz (Coord.). Direito humano à alimentação adequada. Rio de Janeiro: Lumen Juris, 2007.

PIOVESAN, Flávia. Proteção internacional dos direitos econômicos, sociais e culturais. In: SARLET, Ingo Wolfgang. Direitos fundamentais sociais: estudos de direito constitucional, internacional e comparado. Rio de Janeiro: Renovar, 2003. p. 243-249.

SACHS, Ignacy. Inclusive development strategy in an era of globalization. Working Paper. Geneva n. 35, maio 2004. Disponível em: <http://papers.ssrn.com/sol3/ papers.cfm?abstract_id=980233>. Acesso em: 03 dez. 2010.

SACHS, Ignacy. Desenvolvimento includente, sustentável sustentado. [Rio de Janeiro]: Garamond, 2004.

SEN, Amartya. Desenvolvimento como liberdade. São Paulo: Companhia das Letras, 2000 .

SEN, Amartya. Development thinking at the beginning of the $21^{\text {st }}$ Century. In: Conference on 'Development Thinking Practice', of the Inter-American Bank. Washington, Sept. 1996. Disponível em: <http://papers.ssrn.com/sol3/papers. cfm?abstract_id=1126934>. Acesso em 03 dez. 2010.

SEN, Amartya. Development thinking at the beginning of the $21^{\text {st }}$ Century. Paper presented at a conference on 'Development Thinking Practice', of the InterAmerican Bank. Washington, 3-5 Sept. 1996. Disponível em <http://papers.ssrn. com/sol3/papers.cfm?abstract_id=1126934>. Acesso em: $03 \mathrm{dez} .2010$. 
SILVA, José Graziano da; BELIK, Walter; TAKAGI, Maya Takagi (Org.). Combate à fome e à pobreza rural. São Paulo: Instituto Cidadania, 2002.

STEINBERGER, Marília (Org.). Território, ambiente e políticas públicas espaciais. Brasília: LGE, 2006.

VALENTE, Flávio Luiz Schieck (Org.). Direito humano à alimentação: desafios e conquistas. São Paulo: Cortez, 2002.

VEIGA, José Eli da. Desenvolvimento sustentável: o desafio do século XXI. 3. ed. [Rio de Janeiro]: Garamond, 2008.

ZELEDÓN, Ricardo. Desarrollo. In: ZELEDÓN, Ricardo Zeledon. Derecho agrario $y$ derechos humanos. Paraná: Juruá, 2001.

ZIMMERMANN, Clóvis, As políticas públicas e a exigibilidade do direito humano à alimentação. In: PIOVESAN, Flávia; CONTI, Irio Luiz (Coord.). Direito humano à alimentação adequada. Rio de Janeiro: Lumen Juris, 2007. 